\title{
Stakeholders' Practices and Perspectives on Solid Medical Waste Management: A Community Based Study in Accra, Ghana
}

\author{
Emilia A. Udofia',2, Julius Fobil2 ${ }^{2}$, Gabriel Gulis ${ }^{3}$ \\ ${ }^{1}$ Department of Community Health, School of Public Health, University of Ghana, Legon, Ghana \\ ${ }^{2}$ Department of Biological, Environmental and Occupational Health Sciences, School of Public Health, \\ University of Ghana, Legon, Ghana \\ ${ }^{3}$ Unit for Health Promotion Research, University of Southern Denmark, Esbjerg, Denmark \\ Email: eudofia@ug.edu.gh
}

How to cite this paper: Udofia, E.A., Fobil, J. and Gulis, G. (2018) Stakeholders' Practices and Perspectives on Solid Medical Waste Management: A Community Based Study in Accra, Ghana. Journal of Environmental Protection, 9, 1295-1313. https://doi.org/10.4236/jep.2018.913081

Received: October 18, 2018

Accepted: December 8, 2018

Published: December 11, 2018

Copyright $\odot 2018$ by authors and Scientific Research Publishing Inc. This work is licensed under the Creative Commons Attribution International License (CC BY 4.0).

http://creativecommons.org/licenses/by/4.0/

\begin{abstract}
Solid medical waste (SMW) is hazardous and requires specific treatment prior to final disposal. Limited information addresses the management of SMW in non-traditional settings such as in households, traditional birth attendants' (TBAs) homes and chemical seller (CS) shops. A descriptive, exploratory study was conducted to identify major disposal practices and perceived hazards associated with SMW and explore their views regarding segregation as a potential management option. Twenty-nine household members, 10 TBAs and $8 \mathrm{CS}$ who volunteered to participate in the study were involved in 6 focus group discussions (FGDs). Additionally, five key informants in private sector waste management companies were interviewed. FGDs were audio recorded, transcribed and translated, manually coded into themes and sub-themes using an iterative approach, and integrated with data from the interviews. In households, medicines were discarded by dosage forms with solid forms discarded in the household bin, while syrups were mostly emptied into drains. TBAs buried material used for delivery in clients' compounds and CS tended to burn expired medicines or discard them with general waste. Participants perceived the following as hazards associated with SMW: infection transmission, penetrative injury, poisoning and aesthetic nuisance. Despite this awareness, they reported barriers to source segregation as a potential management option. Barriers included implied consumer costs, lack of supportive logistics and operational knowledge, and possible injury. Reported methods of disposing SMW supported earlier studies and could be potentially hazardous if not addressed. Provision of storage facilities, supportive logistics and public sensitization might encourage source segregation as a potential
\end{abstract}


management option for SMW in the community.

\section{Keywords}

Medical Waste, Community, Segregation, Qualitative, Ghana

\section{Introduction}

The management of solid medical waste (SMW) from healthcare facilities has been well studied globally, yet fewer studies address the management of SMW outside hospital settings. Outside the hospital, some of the sources of SMW include households, traditional birth homes and local retail shops for medicines. Although these are generally considered minor sources of SMW, they play important roles in healthcare at community level in developing countries. SMW generated in households is in the form of pharmaceutical waste (expired or unwanted medicines and items contaminated by them), sharps waste (needles, broken glass vials, blades, lancets) and other potentially infectious waste (soiled bandages, gauze, examination gloves) [1] [2] [3]. Inadequate management of household generated SMW could place people at risk, especially waste scavengers, informal waste porters and unsuspecting members of the public. Waste management companies whose staff collect waste from households and who could inadvertently become exposed to these waste components (if they are unprotected) are also at risk.

A traditional birth attendant (TBA) has been described as a person who assists a woman with pregnancy, childbirth, and newborn care and who acquired her skills by working with other TBAs [4]. TBAs have been associated with maternity care, particularly in rural areas of countries including Indonesia, Tanzania, Zambia and Ghana [5] [6] [7] [8]. In spite of the dwindling role of TBAs as institutional deliveries improve, coverage of the latter is still far from universal in Ghana. The 2014 Ghana Demographic Health Survey (GDHS) indicates that $16 \%$ of births are attended by a TBA, while $10 \%$ are attended by a relative or unattended. However, regional differences exist and $41 \%$ of births are attended by TBAs in the Northern Region [9].

Chemical sellers (CS) are another source of solid medical waste (particularly medicines) in the community. In Ghana, CS are persons licensed by the Pharmacy Council to sell over the counter medicines. There are reportedly five chemical shops to every pharmacy [10]. In many communities, they are an initial point of care for minor ailments and have been preferred for their "shorter waiting times, longer business hours, friendly disposition and availability of commodities" [10].

It is generally recommended that SMW be segregated at source to permit the treatment of potentially harmful waste prior to final disposal in healthcare settings. However, observance of these guidelines has been considered impractical 
in community settings and lacks sufficient evidence to support practice [11]. From the stand point of the precautionary principle and infection control, waste generated from patient care should be treated as potentially hazardous until assessment proves it otherwise. There is a dearth of literature describing the management of SMW from community sources in Ghana. To address this, a qualitative evaluation was undertaken within a larger study investigating the management of SMW at community level [12]. We present the perceptions and practices of household members, TBAs and CS regarding disposal and potential harm from SMW in the community. Additionally, their views and those of service providers (private waste contractors) regarding segregation as a potential management option are discussed. The difficulties of waste collection as narrated by service providers have been added to give context to the perspectives of the study participants.

\section{Methods}

\subsection{Study Area and Participants}

The study was conducted in Ga South Municipality, a predominantly urban district in the Greater Accra Region, Ghana. Data was collected in two phases within a larger study investigating solid medical waste from non-traditional sources in the community. The first phase involved a household survey to identify household disposal practices regarding SMW and the second phase involved a household waste audit [12]. Correspondingly, the FGDs and interviews were conducted in June/July, 2014 and January/February, 2015.

Study participants were household members, traditional birth attendants (TBAs), chemical shop sellers (CS) and key informants from accredited private waste management companies in the study area. An eligible household member was an adult informed about the household or resident in the household for at least one month prior to the study period. Household members were recruited by convenience sampling in two large sub-districts (Weija and Amanfrom). Key informants were interviewed at five accredited private waste management companies. They were either directly involved with operations in their companies or conversant with them. TBAs were adults who offered supportive pregnancy care and normal delivery services and CSs were adults who owned and/or worked in a chemical shop in the case of a CS. TBAs and CSs were purposively selected from areas where they were practicing in the district.

\subsection{Study Design}

A descriptive and exploratory design was used, which involved focus group discussions (FGDs) and interviews. FGDs held with household members, TBAs and CS. Pre-identified themes for the focus groups were methods of disposal, hazards associated with SMW and views regarding segregation of SMW as a potential management option. Interviews with key informants at waste management companies focused on service provision and associated challenges. Their views 
regarding segregation of SMW were also explored. Prior to data collection, four field staff were trained in data collection procedures, interpersonal communication skills, and good ethical conduct. Their training lasted a total of six days to cover different aspects of the larger study.

\subsection{Focus Group Discussions with Household Members}

A total of four FGDs were conducted with household members, after which saturation was deemed to have been achieved as no additional information emerged. The first two FGDs were held with two separate groups comprising nine men and five women. Two more FGDs were conducted involving eight men and seven women. The groups were gender based to ensure that they could communicate freely. Flexibility in background characteristics such as level of education and occupation was permitted to gain a broad range of perspectives. A focus group guide was used which was similarly worded and prepared in advance for both groups. Discussions were held in both English and local dialects. The moderator was a health professional conversant with the local dialects. Written consent was obtained from all participants ahead of the discussion. The FGDs were audio-taped by EAU assisted by two field workers who also took notes (one in each group). Sample size was based on an acceptable range of 3 12 participants [13].

\subsection{Interviews with Key Informants at Private Waste Management Companies}

Informed consent was obtained before each interview. All interviews took place between 10 am and $3 \mathrm{pm}$ on two consecutive week days and were conducted in English. Each interview lasted an average of thirty minutes; the rest of the time was spent in travel between the offices, two of which were located outside the Municipality. A phone interview was held with a management staff of one company to obtain information regarding the status of a waste treatment plant for SMW which had not begun operation at the time of the interview. Notes were taken by the researcher during the interviews. The notes were summarized into key points at the conclusion of each interview for affirmation and/or clarification by the informant. The most recent report on waste management was obtained from the Waste Management/Public Health Department at the District Assembly provided information on the status of waste management in the district which augmented accounts given by the key informants and household members.

\subsection{Interviews and Focus Group Discussions with Traditional Birth Attendants and Chemical Shop Sellers}

To inform the content of the FGDs, field staff interviewed TBAs and CS during the first ( 3 TBAs, 3 CS) and second phases (7 TBAs, 5 CS) of the study prior to the conduct of the FGDs. The visits were arranged with the support of a Municipal Assembly staff and informed consent was obtained prior to each interview. 
TBAs were visited at home, while CS were interviewed at the shops between 8 am and 9 am when business was not yet at its peak. Responses were recorded in a questionnaire and additional notes taken separately. FGDs with 7 TBAs (the other 3 were unable to attend) were conducted in both English and local dialects moderated by a trained field staff and a midwife. All communication with the CS were done in English. Observations were made of the group dynamics, noting convergence or divergence of views. In both cases, a poster designed by EAU was used to facilitate the discussion. During visits to the field, refuse dumps and activity at these sites were also observed.

\subsection{Field Staff}

All field staff were adept in speaking the local dialects and assisted EAU with data collection throughout the study and interpreted, where this was necessary. Interpretation during the FGDs with TBAs was done by a midwife in the study area and all CS communicated in English.

\subsection{Data Management and Analysis}

All focus discussions were audio recorded, transcribed and translated into English except those in which English was the language of discussion. The latter were transcribed directly. These were integrated with written notes during the discussions. Each translated transcript was read through carefully several times, manually coded and reduced into pre-determined themes namely "management of SMW", "harm associated with SMW" and "source segregation as a potential management option". The notes were explored for additional themes leading to the emergence of "gender roles" from FGDs with household members and this was added. In the text, narratives have been presented under each theme and illustrated with verbatim quotes. All notes taken during the interviews with the five waste contractors were summarized under three major themes: "service provision to households", "challenges with service provision", and "source segregation as a potential management option". The key points were tabulated.

\subsection{Ethical Considerations}

Ethical approval for the study was obtained from the Noguchi Memorial Institute of Medical Research (NMIMR) Institutional Research Board. Written permission to conduct the study was obtained from the Municipal Chief Executive

(MCE). Clearance for conduct of the study was obtained verbally from community chiefs during a meeting convened by the District Assembly at which the purpose and procedures in the study were explained. Individual informed consent was obtained from all study participants.

\section{Results}

\subsection{Demographic Characteristics of Focus Group Participants}

Demographic characteristics of interviewees are summarized in Table 1. 
Table 1. Demographic characteristics of study participants.

\begin{tabular}{|c|c|c|c|c|}
\hline \multirow{2}{*}{ Participants } & \multicolumn{3}{|c|}{ Characteristics } & \multirow{2}{*}{ Total } \\
\hline & Age range (years) & $\%$ of secondary level education & Male/Female ratio & \\
\hline $\begin{array}{l}\text { Household } \\
\text { members }\end{array}$ & $27-64$ & 82.75 & $17 / 12$ & 29 \\
\hline $\begin{array}{c}\text { Traditional birth } \\
\text { attendants }\end{array}$ & $42-69$ & 50 & $20 / 80$ & 10 \\
\hline Chemical sellers & $22-68$ & 100 & $5 / 3$ & 8 \\
\hline
\end{tabular}

\subsection{Harm Associated with Solid Medical Waste as Perceived by Household Members}

The perceptions about harm associated with SMW centered on HIV and tetanus, particularly with discarded blades and used medical needles. Household members stated that:

"We should throw away blades or it can cause HIV/AIDS." (Female household member)

"With the medical needle, our children can pick it and inject themselves and if the person who used it before has any diseases, they can also be infected by it." (Male household member)

Acute poisoning was another hazard suggested during the focus groups:

"Some medicines are too potent and if care is not taken, children can pick them and swallow which can kill them." (Male household member)

Field observations also revealed that scavengers and informal waste porters conducted their activities without protection (Figure 1) which could predispose them to injuries.

\subsection{Views about Segregation as a Potential Management Option for Solid Medical Waste}

Potential methods of segregation were reported as: wrapping and burial or burning of pharmaceutical waste in a pit, separation and resale of medicine bottles and the use of a separate bin. Participants' views in favour of and against segregation of SMW at source are summarized in Table 2.

Household members

Household members justified segregation as a probable management option for SMW based on potential hazards posed to children in the form of injury and potential transmission of diseases. In spite of these reasons, focus groups revealed several limitations to its implementation. The lack of awareness about segregation of SMW was evident as a male FGD participant stated: "In my home, we don't separate, because we feel it is all waste".

Lack of storage facilities and logistics to support separate collection of SMW appeared to negate the purpose of segregation as noted in the following comments: 


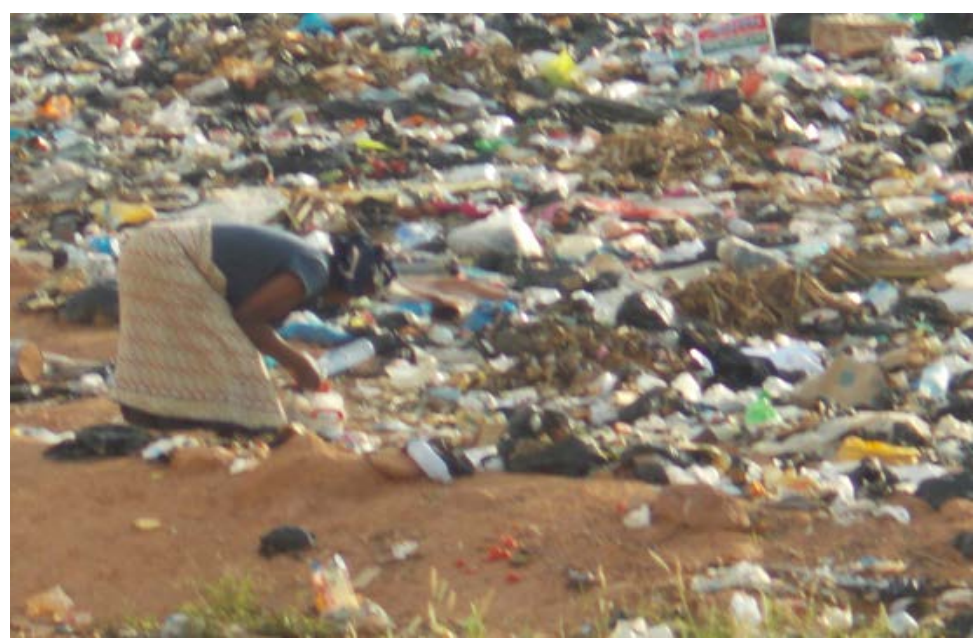

A female scavenger at an open dump site working with bare hands

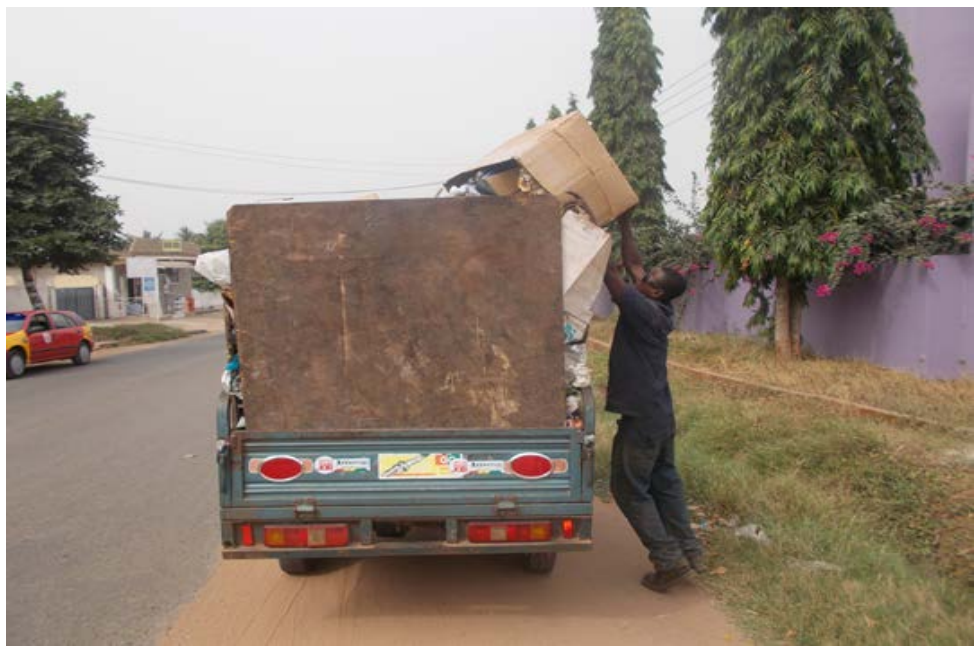

An informal waste porter emptying waste with bare hands

Source: Field work, 2014.

Figure 1. Persons at risk of percutaneous injury.

"I have one bin, so I put all waste together." (Male FGD participant)

"Even if you separate normal waste from it [SMW] in homes, the waste collector comes for it with one vehicle where the two separate wastes are kept together, so there is no need for separation. They will mix them because they use only one vehicle for the waste." (Male FGD participant)

The cost of paying for collection of an additional waste stream was a concern raised by male participants. Male household heads had the role of making payments for services and so a gender perspective emerged:

"// also the money the waste management companies collect is a big problem in this area." (Male FGD participant)

"I think the government should help because the private companies charge a lot." (Male FGD participant) 
Table 2. Stakeholders' views about source segregation of solid medical waste as a potential management option.

\begin{tabular}{|c|c|c|}
\hline \multirow{2}{*}{ Target group } & \multicolumn{2}{|c|}{ Stakeholders' views } \\
\hline & Facilitating factors & Barriers \\
\hline \multirow[t]{6}{*}{ Households } & Community education & Difficulties with storage \\
\hline & Provision of required logistics & Time consuming \\
\hline & Subsidized collection cost & Lack of logistics \\
\hline & & $\begin{array}{l}\text { Difficulty remembering to } \\
\text { segregate }\end{array}$ \\
\hline & & Physical harm \\
\hline & & Affordability \\
\hline \multirow[t]{3}{*}{$\begin{array}{c}\text { Private waste } \\
\text { management companies }\end{array}$} & Business opportunity & Willingness of households to pay \\
\hline & Final disposal site & \\
\hline & Marginal cost recovery & \\
\hline \multirow[t]{2}{*}{$\begin{array}{l}\text { Traditional birth } \\
\text { attendants }\end{array}$} & $\begin{array}{l}\text { Availability of a placenta pit at the } \\
\text { health facility }\end{array}$ & $\begin{array}{l}\text { Distance to the health } \\
\text { facility }\end{array}$ \\
\hline & $\begin{array}{l}\text { Traditional birth attendants } \\
\text { permitted to use placenta pit by } \\
\text { health facility staff }\end{array}$ & Existing norms \\
\hline \multirow[t]{2}{*}{ Chemical shop vendors } & Not applicable & Housing tenure \\
\hline & & $\begin{array}{l}\text { Lack of support for "take-back" of } \\
\text { unwanted medicines from the } \\
\text { community }\end{array}$ \\
\hline
\end{tabular}

On the other hand, women were more concerned about the practical issues surrounding the separation of SMW, one of which was separate storage for SMW: "My house is rented so the separation is a problem ... there is a storage problem." (Female FGD participant) Female household members further pointed out that children were less likely to interfere with SMW if it was mixed with domestic waste in the household bin. When SMW was mixed with household waste, it was hidden from view. They also stated that injury could easily occur if SMW is separated, especially if sharps were present. Therefore, disposing SMW with household solid waste (HSW) would ensure that children avoided it. They agreed that it was sufficient to wrap SMW and discard it in the household bin.

TBAs and CSs

TBAs were asked about the possibility of using a placenta pit at a health facility near them, so that all the placentae were confined to a particular location, where it could be managed appropriately. The nearest health centre did not have a placenta pit at the time the focus group held. Notwithstanding, TBAs were uncertain that facility staff would permit them to do so:

"We have understood this but will the hospital allow us? If they will allow 
us, yes, we will bring it [placenta]." (Male TBA)

Other TBAs had a divergent view. The distance between the communities where the TBAs worked and the location of the health facility was the main barrier (Figure 2):

“... I stay far away. If I accept, I will find it difficult to bring it since I don't have a motor [car], and they are not common here." (Female TBA)

The option to have a placenta pit dug within the communities they served or at their residence (if home births occurred there) was also examined. Housing tenure emerged as a critical factor. Digging pits or modifying property was not

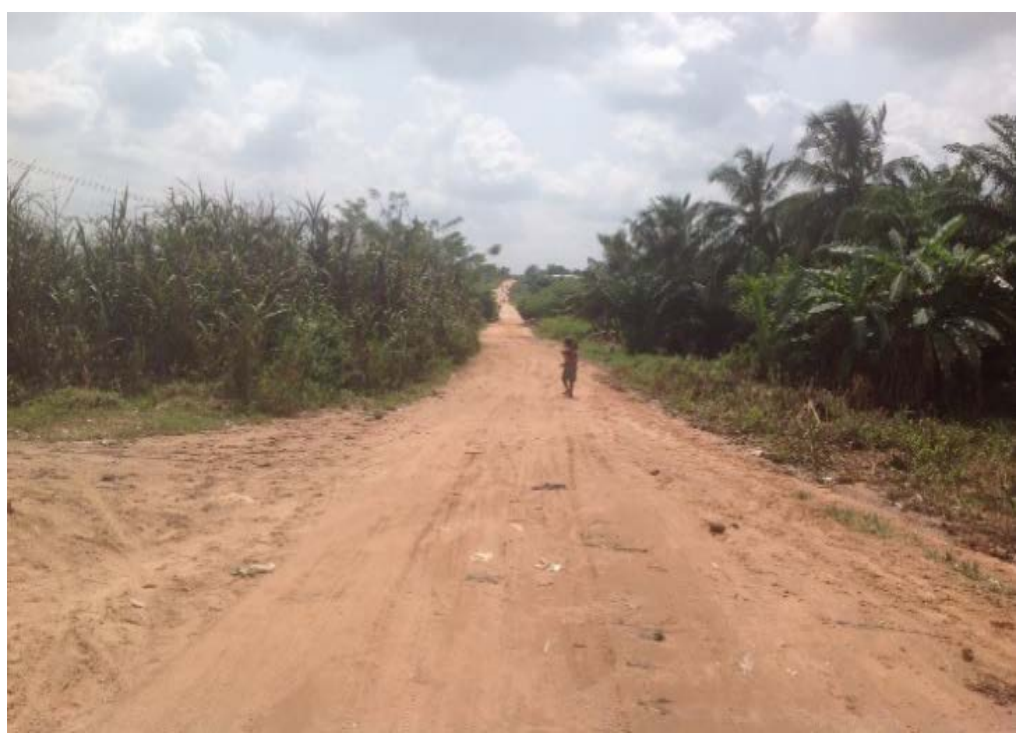

A section of the long road connecting the communities and the health center, vehicles were seen periodically

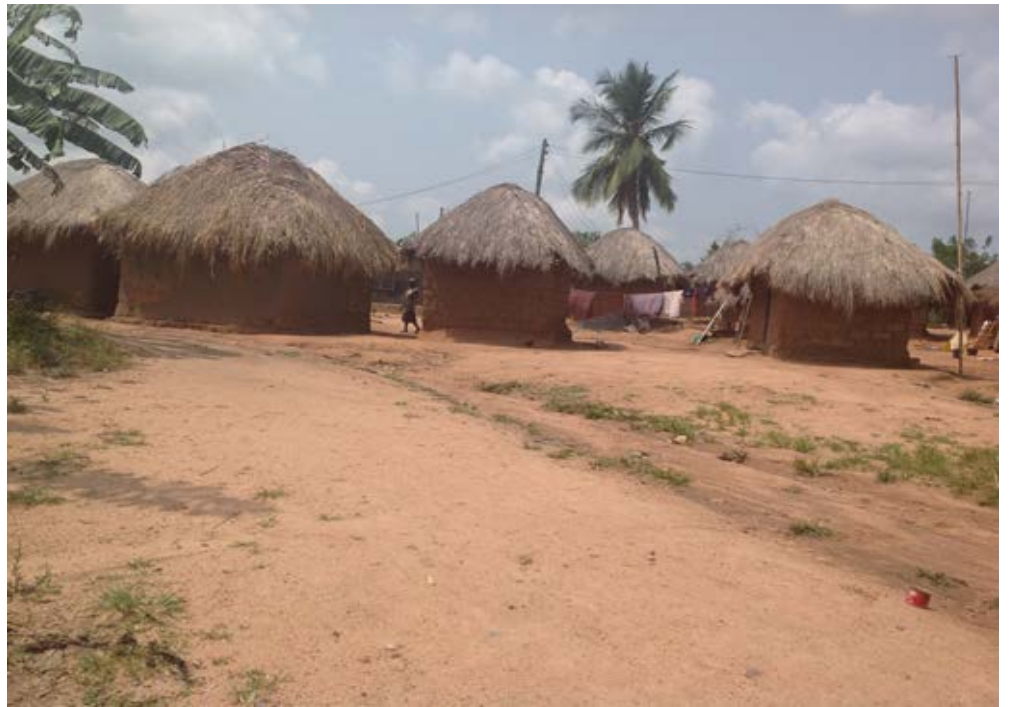

One of the communities in the catchment area of the health center, along the road on the left

Figure 2. Photographs depicting the long distance between the health centre and communities. Source: Fieldwork, 2015. 
acceptable in a compound where accommodation was rented. Conventional practice and suspicion were other barriers. Participants made these comments:

"The landlord will not allow me to be digging pits in his house, but I can also dump it in the latrine." (Female TBA)

"I $t$ will be a problem, even in the hospital some people take their placenta back home. So they won't understand why we are taking their placenta somewhere else. They will think we are going to use it to perform rituals." (Female TBA)

Other participants agreed that it would be difficult to dig placenta pits in the community, except at the health facility, therefore this was not explored further. It was also clear that if the current practice of burying placenta at home was to change, that change had to be initiated first at the health facilities:

"Before people can understand this well, the hospital shouldn't allow them to take the placenta back home, so that others will know that they do not return with it." (Male TBA)

CS felt that other than expired medicines, the bulk of their waste was packaging. They were content to burn/bury expired medicines or place them with other waste in a refuse bin as this was convenient. Offering take back services to the public for unwanted medicines was a moot point because some CS reported they already had difficulties with waste disposal and could not take up additional waste.

Private waste contractors

Interviews with the key informants emphasized the need for a final disposal point. During the study period, there was no centralized treatment plant for SMW. However, a treatment plant is now available and provides services to some hospitals; it also serves as a transfer station. All key informants perceived source segregation as a business opportunity and were willing to collect SMW separately from households if operational costs could be recovered with a marginal profit. Another concern raised by all informants was the ability of the households to pay for the services when provided. The informants expected that separate collection should attract extra costs and they feared this could worsen the existing difficulties with households' payment for refuse collection.

\subsection{On-Site Disposal of Solid Medical Waste}

Households

The focus group discussions revealed there were various options for disposal of SMW: selling the empty medicine bottles to vendors, throwing unwanted medicines into the refuse bin, backyard burning, and dumping them in an empty plot. Waste receptacles varied from cellophane bags to sacks and plastic containers. The influence of dosage forms on disposal methods emerged in both female and male participant groups: 
"... The expired ones [medicines] are buried in the ground. I also empty the expired liquid medicines into the gutter and wash the bottle before I throw it away." (Female FGD participant)

"...I empty syrups into a bowl of water and throw it away with the water. The tablets are thrown in the bin and the waste companies will come for it..." (Male FGD participant)

The indiscriminate disposal of unwanted medicines was also reported: "Any place I find, I will throw it [unwanted medicines] there." (Male FGD participant) However, some effort was made to reduce surface exposure to sharps waste as remarked by a participant: "If I see a syringe, I take the needle off and throw it in the latrine." (Male FGD participant)

Soiled items (e.g. bandages), blood soaked items (e.g. sanitary pads) and disposable items (e.g. condoms) were reportedly wrapped and buried or burnt. Condoms and sanitary waste are not typically considered SMW, but were included in the discussions due to contamination from potentially infected body fluids and/or environmental conditions. Some participants would burn or bury some of the items to protect them from stray animals that forage through household bins outside the dwelling:

"We wrap it [bandages] and burn it." (Female FGD participant)

"Dogs can come for all these items if not kept well. Because of this problem, we dig a pit at home for all bandages and wrap sanitary pads and Pampers and throw them into the pit..." (Female FGD participant)

Condoms were spoken about by male participants. Male condoms were reportedly discarded in the toilet or refuse bins:

"// with the used condom, we put it in the toilet, and also sometimes you will find them floating around in rain water." (Male FGD participant)

"I mix it with general waste and discard it." (Male FGD participant)

Placentae from home births were usually buried by the birth attendant or the woman's spouse. Female participants indicated that the burial of placentae was tied to spiritual beliefs:

"I delivered twice by myself. My grandmother dug a special pit for all those things [afterbirth]. She buried them herself. She doesn't allow anyone to do it because she believes it can cause problems." (Female FGD participant)

Males, on the other hand did not attach any special meaning. They found it necessary to simply place it in a container for disposal:

"I just put it in a rubber [cellophane] bag and then bury it in the ground." (Male FGD participant)

TBAs and CSs

TBAs confirmed the reports made by householders. Anatomical waste (placentae) and sharps waste (razor blades) used during delivery were buried in the compounds of their clients as the TBAs often visited their clients at home. Other potentially infectious waste was either buried or burnt. In the clients' compounds, there was usually no designated pit for placenta(e), so it could be buried 
in more than one place in the compound:

"We don't have one pit for all the placentae. We dig different pits." (Male TBA)

"The reason we don't put them in one pit is that it takes time for us to get deliveries and we will be called to the person's house to do it there. So after that we bury it there." (Female TBA)

One of the TBAs remarked about a traditional belief associated with the burial of placenta:

"I drop the placenta carefully into a pit by not turning upside down. If it is turned upside down, there is a traditional belief that the woman will not be able to conceive again." (Female TBA)

The main type of SMW generated from CS was pharmaceutical waste (expired medicines and their containers). Expired medicines were either burnt elsewhere or added to refuse bins:

"[...] it is not good for expired drugs to be kept for a long time because some of the drugs give a bad odour, so we burn them. [...] When we store expired drugs, I take them to the house. In the house we have a big pit that we burn them in... so I don't have any problem with the community." (Male CS)

"Normally, expired goods in my shop are not burnt since we are many around the place, we don't burn things like that. I add it to the rubbish [...] but if it is syrup, I pour it out and add the bottle to the rubbish." (Female CS)

Packaging accompanying medicines were either taken away or left behind by clients and discarded as general waste. Most of the refuse bins observed during visits in the chemical shops were either empty or contained some packaging. This was attributed to the regular rounds made by the informal waste porters who were paid to collect the waste. One of the CS claimed the medicines in his shop hardly ever expired because they were sold out before then. Two CS returned their expired medicines through a pharmacy or the suppliers who took responsibility for ultimate disposal. Bandages were reported to be purchased by clients, taken away for application and were not often part of the waste they generated. CS did not think that households would have or return leftover medicines because people often bought the quantity they needed. If there were any left overs, these were given to any household members who had need for them. They acknowledged that if SMW were present in uncollected household waste, it posed some risk to children:

“... because there are children walking around who will try to pick, thinking it [tablet] is toffee." (Male CS)

\subsection{Collection of Household Waste Containing SMW}

Excluding placentae, SMW was not usually segregated. It was mixed with household waste and stored in whatever served as the household bin which included cellophane bags, buckets and the standard bins. Participants in household FGD groups expressed dissatisfaction over waste collection because it was sche- 
duled to occur weekly, but it was often delayed:

"Sometimes the refuse will be there for two weeks and they won't come for it and therefore I send it to the communal bin ..." (Female FGD participant)

"The waste management companies do not come for the waste on time. Sometimes for weeks or a month, they haven't come for it." (Male FGD participant)

The delays in waste collection also served as a demotivation to pay for waste collection:

"The waste management companies do not come for the waste on time when the bins are full, so people fall sick and lose their life from diseases like cholera and for that reason they do not pay for the waste and dump it in the rain." (Male FGD participant)

Interviews held with the private sector informants confirmed the challenges associated with waste collection (Table 3).

The scheduled weekly collection from residential premises was often interrupted during the rains due to difficult terrain, including some waterlogged areas. The heavy compactor trucks which got stuck in mud often took several days to dislodge. Occasionally when a truck got stuck, some of the vehicle parts got stolen before the contractors were able to remove it from the location. Consequently, arrangements were made with households to bring their refuse bins to an agreed location where the compactor truck could be parked. All the waste contractors bemoaned the inadequate landfill sites. At the landfills, payments had to be made (in proportion to the waste load) before clearance was given to empty the truck's contents. Similar charges were mentioned by the informants, but the rates fixed by the Municipal Assembly did not take into account the payments at the landfill. They all agreed that it had become necessary to review upwards the service fees paid by households, but this had not happened at the time of the interview. As only one landfill site was functional at the time of the report, this meant that a long distance had to be traveled each time (one and a half hours). Furthermore, the long queues of refuse trucks made it impossible to meet the weekly collection schedule.

\section{Discussion}

Several studies indicate the household bin was the main waste receptacle for tablets and other solid forms, while liquid formulations were emptied in sinks and drains [2] [14] [15] [16]. Since nearly all household waste in Ghana is landfilled, the eventual disposal of medicines in household waste at landfills can potentially contaminate landfill leachate, surface and ground water if there are no facilities for its removal or treatment [16]. Other disposal options reported in the study included burning and burial. Apart from contributing to air pollution, burning pharmaceuticals under sub-optimal temperatures leaves behind partially oxidized residue which may still be active when discharged into the environment [17]. 
Table 3. Main output of interviews with key informants at private waste management companies in the study area.

\begin{tabular}{|c|c|c|}
\hline \multirow{2}{*}{$\begin{array}{l}\text { Private waste } \\
\text { management company }\end{array}$} & \multicolumn{2}{|c|}{ Main output of interviews } \\
\hline & Service provision & Challenges \\
\hline \multirow[t]{6}{*}{ A } & Registration of users & Affordability of monthly dues for users (GHC15) \\
\hline & Bin provision & Difficult terrain \\
\hline & Waste collection: weekly from residential premises & Staff shortage \\
\hline & & Inadequate landfill sites \\
\hline & & Payments at the landfill sites (GHC12 per ton of waste) \\
\hline & & Attack by land guards \\
\hline \multirow[t]{3}{*}{ B } & Registration of users & Inadequate dump sites \\
\hline & Bin provision & \\
\hline & Waste collection: weekly from residential premises & Payments at the landfill sites (GHC $15-18$ ) \\
\hline \multirow[t]{3}{*}{$\mathrm{C}$} & Registration of users & $\begin{array}{l}\text { Difficult terrain, especially during the rains (June/July, } \\
\text { 2014) }\end{array}$ \\
\hline & Bin provision, house stickers & Breakdown of compactor trucks \\
\hline & $\begin{array}{l}\text { Waste collection: weekly from residential premises; more } \\
\text { often from commercial premises }\end{array}$ & \\
\hline \multirow[t]{4}{*}{$\mathrm{D}$} & Registration of users & Difficulty getting users to pay for services \\
\hline & Easy payment plan & Difficult terrains during rains \\
\hline & Bin provision, house stickers & Inadequate dump sites \\
\hline & Waste collection: weekly from residential premises & Payment at dumpsite (GHC 20) \\
\hline \multirow[t]{4}{*}{$\mathrm{E}$} & Registration of users (sometimes free) & Difficult terrain during the rains \\
\hline & & $\begin{array}{l}\text { Limited access to landfill sites due to long queues, some } \\
\text { sites do not open on Sundays }\end{array}$ \\
\hline & Bin provision, house stickers & \\
\hline & Waste collection: weekly from residential premises & \\
\hline
\end{tabular}

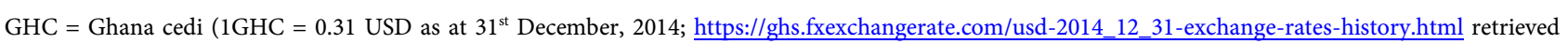
12th November, 2018).

The storage of waste containing sharps in non-rigid receptacles such as cellophane bags can be hazardous to those charged with the responsibility of conveying waste to the point of collection. Public sensitivity about HIV in relation to children as demonstrated by household members in the present study has been reported in an earlier study in South Africa [18]. Dumping sharps into a pit latrine, while eliminating the possibility of surface accessibility, creates a potential hazard for those who manually evacuate the pit for reuse. Needles should either be incinerated or buried in pits with a cement base to preclude the possibility of injury [19]. The syringe component of a needle is made of plastic which is non-biodegradable. These plastics can persist in the environment for 1000 years and contribute to pollution [20].

Based on its intrinsic value, it has been argued that placenta cannot be classified as medical waste [21] [22]. Contrariwise, the requirement for standard pre- 
cautions to be observed in its handling within biomedical contexts, implies it is medical waste [23]. Apart from women who had home births, it was also reported that in some cases, placentae were taken home by women who had institutional births. This situation has also been reported in Cameroun and Australia [23] [24]. This is often tied to ethical, religious and cultural beliefs as reported here. In the present study, the placentae were reportedly placed in earthen pits where they can undergo natural decomposition. In flood prone areas, infiltration from these pits can potentially contribute to organic pollution of surface water, if not adequately managed. This is implied in the recommendation by WHO that 0.5 litres of soil infiltration per placenta be allowed in estimating the dimension of a placenta pit, among other factors [25]. However, distance to health facilities where appropriately constructed placenta pits exist precludes its use when a home birth occurs as narrated by the TBAs. TBAs lack logistics to convey placental waste to healthcare facilities and doing so may contradict cultural norms. Furthermore, the health facility closest to community where the participating TBAs practiced lacked a placenta pit at the time. Elsewhere it has been suggested that placenta can be diverted to therapeutic use [26]. For this to be practicable, further research is needed to ascertain its cultural and religious acceptability, the local prevalence of medical conditions requiring placental products and the capacity of existing laboratories to safely process products to meet therapeutic needs.

Participants recognized that SMW can be associated with hazards and identified children as being at risk. In spite of this awareness, they were less inclined to accept segregation of SMW as a potential management option for SMW in non-traditional settings. First, public education about SMW is required. There must be a clear definition of SMW, identifying what items will be collected from households and other sources in the community. Furthermore, it should address safe storage, collection systems, costs and convenience of collection from households and other sources. The negative views strongly held by the women regarding segregation suggest that it is essential to gain women's acceptance. A previous study on segregation of solid waste demonstrated the positive influence of female gender on sorting [27].

If "take-back" systems should be institutionalized with chemical sellers who reside in the community, storage facilities, regular collection, training and monitoring will be required, and their own waste disposal needs should be taken into account. Improving waste collection frequency by the private sector should minimize aesthetic nuisance and potential injury from inadvertent exposure to SMW. Public attention to the management of solid medical waste in the community is an emerging issue. However, the shared responsibility for patient care by family or household members suggests that it cannot be ignored. Where public guidance on the appropriate management of SMW is addressed proactively, it can complement existing efforts to achieve a sustainable environment by minimizing potential contamination of environmental media. 
Based on the results of this study, a locally available, affordable and feasible option for sterilizing SMW in non-traditional settings should be explored. This will ensure that SMW can be safely disposed with other solid waste. Costs may impair widespread use. An alternative is to consider pick-up systems from points of solid medical waste generation, supported by intensive public/community education, logistic arrangements and minimum cost. Sharps waste, whether treated or not, will require specific removal to obviate penetrative injury occurring to unsuspecting persons particularly children.

Strengths and limitations

The inability of the first author to speak the local dialect interfered with spontaneity in the discussions and capacity to gain further depth on some of the issues. It is also possible that some meanings or the intensity of them may be lost during translation. However, EA and the field staff together shared reports of perspectives from the focus discussions and field observations that would not have been achieved if the author had worked on her own. The health professionals who assisted with translation lend support to the credibility of this report. Although the sampling method precludes generalization beyond the study area, the study highlights useful information for planning medical waste management. It informs the need for further research on the subject and advocates for attention to community sources of SMW in policy direction.

\section{Conclusion}

Household members adopted different methods for disposal of SMW, similar to those reported in studies elsewhere. They were familiar with hazards associated with SMW, but had divergent and gender related views regarding segregation of SMW as a potential management option. Barriers to segregation were mainly the implied cost, absence of storage facilities and logistics to support practice. Females were less inclined to segregate SMW. TBAs and CS had limited options for disposal of SMW and used methods that could potentially pollute the environment. This qualitative study provides depth to the management of SMW lacking in earlier studies. The information is useful for waste management planning, informs interventions for public environmental education and should stimulate further research.

\section{Acknowledgements}

The authors gratefully acknowledge the Building Stronger Universities in Developing Countries-Platform for Human Health, DANIDA and the University of Ghana, which provided funding for the larger study of which this study is a part. We are also grateful to the Ga South Municipal Assembly, its Health Directorate, Chiefs, communities and the field staff for their support during the conduct of the study. The authors are grateful for the helpful advice of Dr. Edith Clarke and Dr. Henry Lawson. 


\section{Funding}

The funding for this research came from a $\mathrm{PhD}$ fellowship grant awarded to EAU by Building Stronger Universities in Developing Countries-Platform for Human Health of the Danish Government, in collaboration with the University of Ghana. Other than training in basic research methods and proposal development, the funders played no further role in this research.

\section{Authors' Contributions}

EAU conceived, designed and analyzed the study. Methodology was reviewed by GG and JNF. Data collection was coordinated by EAU. All authors made significant contributions to the writing of the manuscript. The final manuscript was reviewed and approved by all authors.

\section{Conflicts of Interest}

All authors declare that they have no competing interests.

\section{References}

[1] Olowokure, B., Duggal, H. and Armitage, L. (2003) The Disposal of Used Sharps by Diabetic Patients Living at Home. International Journal of Environmental Health Research, 13, 117-123. https://doi.org/10.1080/0960312031000098044

[2] Sasu, S., Kummerer, K. and Kranert, M. (2012) Assessment of Pharmaceutical Waste Management at Selected Hospitals and Homes in Ghana. Waste Management \& Research, 30, 625-630. https://doi.org/10.1177/0734242X11423286

[3] Subratty, A. and Nathire, M.H. (2005) A Survey on Home Generated Medical Waste in Mauritius. International Journal of Environmental Health Research, 15, 45-52. https://doi.org/10.1080/09603120400018915

[4] WHO (1992) Training of Traditional Birth Attendants (TBAs) - A Guide for TBA trainers (D. o. F. H. Programme of Maternal and Child Health and Family Planning, Trans.). In: K.I. Cabral M., Kumar V. and Mehra L., Eds., WHO, Geneva, Switzerland, 2.

[5] Aborigo, R.A., Allotey, P. and Reidpath, D.D. (2015) The Traditional Healer in Obstetric Care: A Persistent Wasted Opportunity in Maternal Health. Social Science \& Medicine, 133, 59-66. https://doi.org/10.1016/j.socscimed.2015.03.046

[6] Mahiti, G.R., Kiwara, A.D., Mbekenga, C.K., Hurtig, A.K. and Goicolea, I. (2015) "We Have Been Working Overnight without Sleeping": Traditional Birth Attendants' Practices and Perceptions of Post-Partum Care Services in Rural Tanzania. BMC Pregnancy Childbirth, 15, 8. https://doi.org/10.1186/s12884-015-0445-Z

[7] Phiri, S.W., Fylkesnes, K., Ruano, A.L. and Moland, K.M. (2014) "Born before arrival": User and Provider Perspectives on Health Facility Childbirths in Kapiri Mposhi District, Zambia. BMC Pregnancy and Childbirth, 14, 323. https://doi.org/10.1186/1471-2393-14-323

[8] Titaley, C.R., Hunter, C.L., Dibley, M.J. and Heywood, P. (2010). Why Do Some Women Still Prefer Traditional Birth Attendants and Home Delivery?: A Qualitative Study on Delivery Care Services in West Java Province, Indonesia. BMC Pregnancy Childbirth, 10, 43. https://doi.org/10.1186/1471-2393-10-43

[9] GSS, GHS and ICF Macro (2015) Ghana Demographic and Health Survey 2014. 
Ghana Statistical Services (GSS), Ghana Health Service (GHS), ICF Macro, Accra, 115.

[10] Letbetkin, E., Tracy, O., Dzasi, K., Keyes, E., Shelus, V., Mensah, S., et al. (2014) Injectable Contraceptive Sales at Licensed Chemical Seller Shops in Ghana: Access and Reported Use in Rural and Periurban Communities. International Perspectives on Sexual and Reproductive Health, 40, 21-27. https://doi.org/10.1363/4002114

[11] Ward, D. (2002) Community Infection Control: What Is the Evidence? British Journal of Community Nursing, 7, 304-308. https://doi.org/10.12968/bjcn.2002.7.6.10475

[12] Udofia, E.A., Gulis, G. and Fobil, J. (2017) Solid Medical Waste: A Cross Sectional Study of Household Disposal Practices and Reported Harm in Southern Ghana. BMC Public Health, 17, 464. https://doi.org/10.1186/s12889-017-4366-9

[13] Tracy, S.J. (2013) Qualitative Research Methods: Collecting Evidence, Crafting Analysis, Communicating Impact. John Wiley \& Sons, New York.

[14] Abahussain, E.A., Ball, D.E. and Matowe, W.C. (2006) Practice and Opinion towards Disposal of Unused Medication in Kuwait. Medical Principles and Practice, 15, 352-357. https://doi.org/10.1159/000094268

[15] Bound, J.P. and Voulvoulis, N. (2005) Household Disposal of Pharmaceuticals as a Pathway for Aquatic Contamination in the United Kingdom. Environmental Health Perspectives, 113, 1705-1711. https://doi.org/10.1289/ehp.8315

[16] Kummerer, K. (2009) The Presence of Pharmaceuticals in the Environment Due to Human Use-Present Knowledge and Future Challenges. Journal of Environmental Management, 90, 2354-2366. https://doi.org/10.1016/j.jenvman.2009.01.023

[17] Tong, A.Y., Peake, B.M. and Braund, R. (2011) Disposal Practices for Unused Medications around the World. Environment International, 37, 292-298.

https://doi.org/10.1016/j.envint.2010.10.002

[18] de Waal, N., Rabie, H., Bester, R. and Cotton, M. (2006) Mass Needle Stick Injury in Children from the Western Cape. Journal of Tropical Pediatrics, 52, 192-196. https://doi.org/10.1093/tropej/fmi094

[19] WHO (2014) Treatment and Disposal Methods. In: Chartier, Y., et al., Eds., Safe Management of Wastes from Health-Care Activities, 2nd Edition, World Health Organization Press, Geneva, 105-145.

[20] Pynthamil, S.R. and Amarnath, J. (2011) Study on the Composition of Municipal Solid Waste in Kanchipuram Municipality. International Journal of Applied Bioengineering, 5, 40-43.

[21] California State Department of Health Services C. (1997) Revision of Policy Regarding Waste Placentas. Health and Welfare Agency, Sacramento.

[22] Helsel, D.G. and Mochel, M. (2002) Afterbirths in the Afterlife: Cultural Meaning of Placental Disposal in a Hmong American Community. Journal of Transcultural Nursing, 13, 282-286. https://doi.org/10.1177/104365902236702

[23] Burns, E. (2014) More than Clinical Waste? Placenta Rituals among Australian Home-Birthing Women. The Journal of Perinatal Education, 23, 41-49. https://doi.org/10.1891/1058-1243.23.1.41

[24] Manga, V.E., Forton, O.T., Mofor, L.A. and Woodard, R. (2011) Health Care Waste Management in Cameroon: A Case Study from the Southwestern Region. Resources, Conservation and Recycling, 57, 108-116. https://doi.org/10.1016/j.resconrec.2011.10.002

[25] WHO (2014) Disposal of Pathological Waste. In: Y.C., et al., Eds., Safe Management 
of Waste from Health-Care Activities, WHO Press, World Health Organization, Geneva, 297-299.

[26] Barry, C.E. (1994) Where Do All the Placentas Go? Canadian Journal of Infection Control, 9, 8-10.

[27] Owusu, V., Adjei-Addo, E. and Sundberg, C. (2013) Do Economic Incentives Affect Attitudes to Solid Waste Source Separation? Evidence from Ghana. Resources, Conservation and Recycling, 78, 115-123.

https://doi.org/10.1016/j.resconrec.2013.07.002 